\title{
A Study on the Impact of the Sudden Change to Online Education on the Motivation of Higher Education Students
}

\author{
Salim Al-Hashmi ${ }^{1}$ \\ ${ }^{1}$ The University of Technology and Applied Sciences, Oman \\ Correspondence: Salim Al-Hashmi, The University of Technology and Applied Sciences, Oman. E-mail: \\ salim.alhashmi@nct.edu.om
}

Received: June 2, $2021 \quad$ Accepted: July 4, $2021 \quad$ Online Published: July 14, 2021

doi:10.5539/hes.v11n3p78 URL: https://doi.org/10.5539/hes.v11n3p78

\begin{abstract}
This study investigates the extent to which students' motivation has changed following the decision to offer all courses entirely online as an emergency remote teaching (ERT). Many scholars describe online learning as the future of education. This mode will soon replace on-campus instruction; thus, such a study is important for higher education institutions (HEIs) that decide to use technology platforms at the times of unpredicted crises. Recent research has focused attention on student motivation in online learning contexts. However, this project results from the sudden transformation to remote online learning caused by COVID-19. The study involved 20 students from an Omani university who participated in four focused group discussions. The findings revealed that students' motivation in remote online learning is impacted by several academic factors (e.g., teachers and lack of group work) and non-academic factors (e.g., internet connectivity and family obligations).
\end{abstract}

Keywords: motivation, emergency remote teaching, self-determination theory

\section{Introduction}

COVID-19 has unprecedentedly hit the world and crippled many social and economic sectors, including higher education (Tamrat 2020; Rahiem 2021). Thoroughly analysing the measures taken by 20 countries worldwide, Crawford et al. (2020) found that universities have responded differently to the staggering threats caused by COVID-19. The responses depended on the number of students and the governments' structures. These measures included temporary campus closures, the complete shift of education from face-to-face to online instruction, or classes offered on campus with strict social distancing measures.

In Oman, the Covid-19 Supreme Committee announced the suspension of all classes in Higher Education Institutions and asked the concerned to look for alternatives to face-to-face education ("Covid-19 Supreme Committee Holds First Meeting”, 2020). Some HEIs took a more complicated approach by completely shutting down, waiting for the new academic year to begin and starting classes as usual. Nevertheless, as the pandemic continued to threaten people's lives, students have been unable to attend their colleges and universities until recently, necessitating the classes' delivery using various electronic platforms. This complete shift to online learning was a new experience that came with unforeseen challenges for students, teachers and administrators (Mohmmed et al., 2020).

Oman's University of Technology and Applied Sciences suspended all classes at the end of March 2020 and switch most exams into home assignments. For general foundation programme (GFP) students, the decision to conduct final exams was delayed until the beginning of September 2020, anticipating that the pandemic would be over. Then, the university administration decided to rely on the students' continuous marks to determine their final results. By the end of September 2020, the university announced that all classes would be online and that students should take the necessary preparations to ensure their studies would not be disrupted during the semester.

\section{The Research Questions}

Five questions were devised to achieve this project's objective to examine the impact of the sudden change to remote online learning on students' motivation and commitment to their studies. They include the following:

1. What motivation changes do the sample students perceive during ERT?

2. What academic extrinsic factors affect the sample students' motivation in ERT?

3. What non-academic extrinsic factors affect the sample students' motivation in ERT?

4. How do students perceive the differences and similarities between ERT and on-campus education?

5. What can be learned from the changes in students' motivation during ERT that will be useful to HEI teachers and administrators? 


\section{Importance of the Research}

The current study is crucial to understanding how the shift from face-to-face education to remote online education impacts students' motivation and commitment to their studies, initiated by COVID-19. In Oman, there has never before been a time similar to when almost all HEIs shifted completely to online education through electronic platforms. Therefore, research in this area benefits all stakeholders, including students, academics and policymakers. This study helps shed light on students' attitudes towards online learning and what aspects of online learning encourage autonomous learning. The findings can be generalised to other contexts because students worldwide share many experiences after the shutdown of HEIs due to the pandemic.

Unlike most studies on COVID-19 and their effect on education that have used quantitative tools, this study provides authentic thoughts from the experiences of students who shared their feelings openly about their experiences during their first in-home-studying semester.

\section{Literature Review}

\subsection{Online vs Emergency Remote Teaching}

A recurring theme in recent literature that addresses teaching during the COVID-19 era is emergency remote teaching (ERT). However, it should be noted here that the concept of ERT in times of emergencies and crises is not considered new, as it has been applied in many places in the world. For example, radio and DVD were the ideal way to educate students in Afghanistan after the outbreak of several wars in the country (Davies \& Bentrovato, 2011). The concept has also been applied in the Palestinian territories by developing several programs on the Internet to avoid the constant closure of schools (Shraim \& Khlaif, 2010).

With the emergence of the current pandemic, many educational institutions needed to act quickly and started to deliver their education through electronic platforms. This sudden shift led several researchers to incorrectly describe this mode of teaching as online teaching at the beginning of the crisis (e.g., Dhawan, 2020; Rapanta et al., 2020). Therefore, it is essential to distinguish between online teaching and ERT. Hodges et al. (2020) explained that ERT is changing the mode of education from an on-campus to online mode in response to an unforeseen crisis. However, these institutions have a specific plan to return to in-campus education once the disaster is over.

Trust and Whalen (2020) contended that the pandemic made it evident to all educational institutions that teachers received neither sufficient training nor preparation to cope with technology-dependent circumstances. Thus, ensuring education's availability to all students away from campus proved challenging. Their study included 325 participants; they found that teachers who quickly adapted to online teaching as a form of ERT were those who frequently used technology in their classes before the pandemic's outbreak. This finding corresponds to the observations of Foulger et al. (2017) and Gares et al. (2020): at times of need, teachers are unprepared to design, prepare or deliver instruction using technology due to poor training.

Because educational institutions adopt ERT in times of emergencies, Hodges et al. (2020) recommended that researchers and educators refrain from categorising ERT as an online form of education for several reasons. First, ERT is a temporary solution to the sudden stoppage of teaching because of an unexpected crisis. In contrast, online learning and teaching are well-planned and prepared to be the standard form of delivery of a particular course. Second, the decision to use ERT usually occurs suddenly to provide students with access to teaching and ensure learning continuity. However, online learning depends on the built-up learning community and provides students with extra-curricular activities and social assistance. Third, the sudden switch to ERT is usually uncomfortable for both teachers and students because of the change's pace and requirement that teachers are technology experts. Conversely, in online learning, teachers and students are equipped with many resources to facilitate teaching and learning smoothly.

\subsection{Motivation}

Motivation is a crucial aspect that affects students' learning and achievement (Chen \& Jang, 2010). Studies on the importance of students' motivation have suggested that it is one of the leading causes of active engagement in studying. Motivated students are more likely to be interactive, creative and persistent (Hatnet et al., 2011). Although students' motivation is very important for educators, Schwan (2021) states that it is very difficult to be measured and evaluated and teachers need to study how their students behave or ask them questions to identify their level of motivation.

Even though motivation has been discussed extensively in literature, it is clear that there is no consensus among scholars about the definition of motivation. The literature available offers different definitions for students' motivation because of the complexity of the term and the changes in understanding the concept over the years (Dörnyei, 2000; Rahiem, 2021). Dörnyei (1998) argued that motivation 'is responsible for determining human behavior by energizing it and giving it direction' (p. 117).

\subsection{Self-determination Theory}

One way to understand motivation and grasp its complexity is by reviewing the established theories on the concept. 
One of these theories is the self-determination theory (SDT), which was formed in 1985 by Edward L. Deci and Richard M. Ryan. SDT is 'an empirically derived theory of human motivation and personality in social contexts that differentiates motivation in terms of being autonomous and controlled' (Deci \& Ryan, 2012). Because of its unique explanation of motivation, Pintrich and Schunk (2002) described the theory as 'one of the most comprehensive and empirically supported theories of motivation available today'. The current study benefited from two main aspects of SDT: the needs that people have to achieve a particular task and the classification of motivation. The study's research questions and the interview items were developed based on these two aspects.

According to Deci and Vansteenkiste (2004), SDT explains that people are generally motivated by three needs: autonomy (the feeling that a person is in control), competency (the sense that a person is able to achieve a specific task), and relatedness (the feeling that a person is related to others and to the social surroundings).

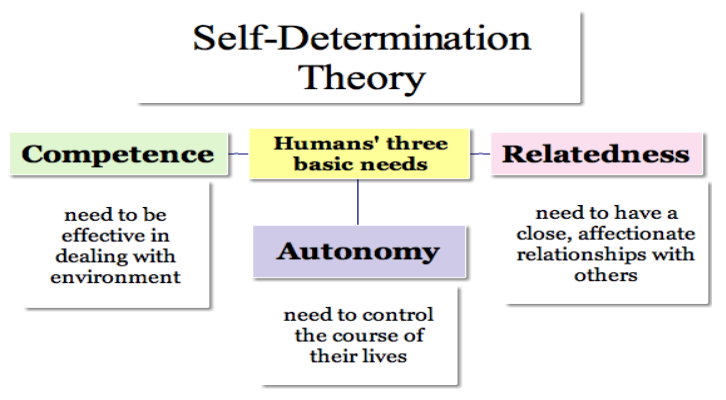

Figure 1. Human basic need in SDT

Source: Ackerman, C. E. (2020). Self-determination theory of motivation: Why intrinsic motivation matters. Positive Psychology.

The second aspect of SDT that makes it important for this study is its distinctive classification of motivation. SDT classifies motivation into three types: intrinsic motivation, extrinsic motivation and amotivation (Deci \& Ryan, 2012). Dörnyei (1998) defined intrinsic motivation as learners performing tasks for their own benefit and achieving personal satisfaction, while extrinsic motivation is performing tasks and expecting a reward in return or to avoid punishment. The third type of motivation is amotivation which refers to a person's lack of interest to achieve a particular task.

Although this study argues that online learning is different from ERT, it is fair to claim that the use of SDT to study motivation in an ERT context is similar to using SDT to study motivation in an online learning setting for two reasons. First, there is a lack of research about students' motivation in an emergency remote teaching (ERT) setting. Second, many educational institutions worldwide shifted from in-campus education to online learning as the primary mode of education during the current pandemic. Therefore, students are impacted by the same personal, environmental, and social factors affecting students in a real online learning context.

Chen and Jang (2010) argued that there are several reasons for choosing SDT as a theoretical background to study motivation in online learning contexts. First, SDT addresses issues like autonomy, relatedness and competency, which are similar to online learning characteristics. It also discusses the obstacles that students might experience during their studies. Second, SDT is not limited to looking at how students' motivation progresses; instead, it provides the steps of how to facilitate students' motivation in an online setting. Third, SDT focuses on the students' social environment as a factor that affects their motivation.

Song (2000) offered another perspective of the types of motivation in an online environment and explained that students are affected by three sets of factors: internal, external and personal. Internal factors refer to educational programmes and how their structures might affect student motivation. External factors refer to the impact of the online learning setting on students' motivation. Personal factors refer to the student's personality and how it is reflected in their motivation.

According to Keller (2008), looking at motivations that can fit all contexts is more valuable than finding a particular definition of motivation in online learning. He explained that teachers nowadays depend on different technology to deliver instruction to students and facilitate their learning to increase enthusiasm. Therefore, motivation in all learning contexts might be triggered because of the following five principles:

1. Students' curiosity, caused by their interest in knowing what they lack

2. Students' belief in the matching of what they are learning with their goals

3. Students' belief the learning tasks are achievable

4. Students' anticipation and satisfaction with the results of the learning tasks

5. Students' ability to continually self-regulate their learning 
Studies that investigated the impact of online learning on students' motivation are not recent. For example, a study was conducted by Kim and Frick (2011) to investigate the factors that stimulate students' motivation in direct self-learning and to investigate the level of learner motivation. Additionally, the researchers determined how levels change during a course's progression to identify the factors associated with changing motivation. The study concluded that four primary factors affect the learner's motivation: interest, awareness of the learning's importance, self-confidence and satisfaction. The correlation of these factors with direct self-learning enables the learner to achieve the learning goals successfully. The study concluded that students' motivation and satisfaction increase in direct self-education when the content is relevant to the learner's life and how easily they interact with technology. Other factors include students' desire for continuous self-learning, the belief that it is their right to learn and the reinforcement and support students received at the beginning and during the lessons.

A 2011 study conducted in New Zealand concluded that learning motivation is a complex and intertwined process. Learners in face-to-face education were not driven by internal motivation, as many studies suggested. This finding makes it necessary to consider the educational situation factors during the learning environment design, set goals and open the door for discussions and choices to motivate students to achieve the learning tasks (Hartnett et al., 2011).

Other studies have shown that students start online courses highly motivated and might lose motivation because they grow bored with technology. Other studies attributed students' dropping-out to a lack of motivation because of students' attitudes or the inability to cope with using technology in online learning contexts (Kim \& Frick, 2011). Schwan (2021) believes that motivating students to finish class work and get good result is extremely difficult during a time when the situation is hard on everyone. Therefore, students should be involved in the learning process and motivation should be discussed now more than before.

\section{Methodology}

Choosing a suitable research methodology is determined by the type and features of the research problem. To achieve the objectives of this project and after considering the different research methods carefully, the researcher found the qualitative method approach appropriate because it reveals more authentic findings, as viewed by Cohen et al. (2011).

This study used the focus group discussion (FGD) as its primary research method. FGDs are a qualitative research method where the researcher interview more than one person at the same time to have their thoughts and experience on a particular subject (Bell, 2014. The choice of this method was made for several reasons. First, FGDs give the participants the comfort to give their opinions while being in a group. Second, participants motivate each other to speak up and share their thoughts. Third, it is useful for participants with similar backgrounds and experiences, which applies to this study's participants.

Several issues were considered when conducting FGDs. Although FGDs consume less time by interviewing several participants simultaneously, the interviewees' interactions and resulting thoughts make FGDs different from interviews (Daniel \& Harland, 2017). In addition, Bell (2014) advised researchers to be alert when conducting FGDs and try their best to minimise individual participants' expected dominance that might negatively affect the other interlocutors' participation.

\subsection{Setting and Participants}

The study took place at Oman's University of Technology and Applied Sciences (Nizwa), formerly Nizwa College of Technology, in Semester 1 of the 2020-2021 academic year. The main reason for selecting this setting is the researcher's familiarity with the context, which reduced the time and cost to carry out this project. The researcher is also familiar with students' personalities and attitudes due to his 11 years of experience handling students' concerns.

The participants are first-year students enrolled in the GFP. This programme prepares students for their credit courses by improving their English, maths and IT skills. I chose 20 students; 10 females and ten males were from different geographical locations. Of the 20 students, I selected ten participants from the newly admitted students and chose the other ten from previous intakes. This selection gave the study more variables and enriched the data with different perspectives. New students' expectations and experiences differed between those students who spent one semester or more in the university.

Due to the restrictions imposed, all FGDs were carried out online through Microsoft Teams. The participants were familiar with the platform because they used it for their online classes. I asked each group seven questions and asked each group member to take turns answering each question. For the sake of clarity, the FGDs are labelled as FGD1 (new intake female students), FGD2 (new intake male students), FGD3 (old female students) and FGD4 in the findings (old male students).

\subsection{Reliability and Validity}

The reliability and validity of the research methods employed for this project was maintained. Reliability refers to the internal consistency of responses, whereas validity means the extent to which a study measures the phenomenon or concept under investigation (Bowen, 2009). A standardised method was used to collect the required data to ensure the consistency of the responses. In addition, participants received no payment or incentives, and they knew 
they were free to withdraw from the FGDs at any point.

To ensure content validity, two experts in the field assessed the FGD questions against the objectives and research questions. Their feedback helped in rewording some of the FGD questions to make them more tangible. Moreover, the participants commented on the accuracy of the main ideas transcribed at the end of each session.

Furthermore, a pilot FGD was carried out to ensure that students understood the questions' wording and provided suggestions for improvement. The pilot FGD was a chance for me to acquire the necessary experience and anticipate students' doubts.

Bearing in mind the students' English proficiency, the four FGDs were conducted in Arabic, the students' native language. The decision to use Arabic was because the language in qualitative data collection has a significant effect on 'data accuracy and authenticity, rapport-building and the construction of shared understanding' (Welch \& Piekkari, 2006). Thus, using the participants' native language enables accurate, authentic communication.

\subsection{Ethical Issues}

Considering ethical issues is essential in studies investigating people's perceptions and collecting their ideas (Cohen et al., 2011). Thus, the participants were dealt with according to the ethical issues' guidelines. For example, participants were asked to sign a consent form, and they were provided with clear information about the research purpose and how their ideas and opinions would be used. Moreover, they were informed at the beginning that they had the right to withdrawal at any time. Participants were treated with dignity and equality, regardless of age, nationality or gender. Additionally, they were assured that none of their personal information would be disclosed, and they would remain anonymous (Bell, 2014; Cohen et al., 2011).

\subsection{Data Analysis}

The FGDs were audio recorded, and the main ideas were transcribed. Then, the data were coded and grouped based on themes. These themes were used as the headings and sub-headings of the finding. Based on findings after studying a number of publications, Nowell et al. (2017) suggested that thematic analysis provides researchers with many advantages. For one, the thematic analysis's flexibility is functional when a researcher finds it essential to modify their projects' needs. The analysis is also more convenient for novice researchers who are not well-versed in other qualitative data analysis methods' theoretical and technological backgrounds. Moreover, thematic analysis is a valuable method that elicits participants' different thoughts and draws on how far these thoughts resemble each other.

\section{Findings}

In this section, the findings from the four FGDs are presented based on themes and the students were asked seven questions during each FGD. It should be noted here that any reference to "online learning" in this section of the study is due to the use of online learning as the dominant mode of teaching here in Oman during the pandemic. Moreover, students and teachers comfortably use the term "online learning" to refer to emergency remote teaching and therefore the term was used to establish a common understanding.

\subsection{First Impressions and Students' Expectations}

Most students in the four FGDs expressed their enthusiasm at the beginning of the semester after knowing their classes were officially going online. They all expected this switch, and they were not surprised because other HEIs in Oman had taken the same measure.

At the beginning of the semester, more than half of the participants felt that shifting education to an online platform was advantageous because it removed the daily commute to the university campus and enabled close proximity to their families at this difficult time.

Each of the ten new intake students revealed that they felt the need to be at the university from the beginning to experience the university's atmosphere. They wanted to meet their teachers and peers in-person and determine what a university student's life looks like on campus.

When asked about their comfort with using technology, most participants felt they could cope with technology; however, their main concern was the strength and availability of internet service in their residential areas.

\subsection{Academic Factors Affecting Extrinsic Motivation}

\subsubsection{Teachers}

In the four FGDs, students expressed that teachers' style impacted their motivation in different ways. For some students, particularly in FGD1 and FGD2, students relied heavily on their teachers and considered them one of the essential factors of staying encouraged throughout the semester. One student said:

My teachers stayed with me up to midnight to help me understand a grammar point that I couldn't get during our online session. If she did that, it means that there is someone who cares about my education, and definitely, this will encourage me.

Other students expressed their frustration about their tutors' teaching styles. They found their instructors uninteresting and unprepared for technology-based teaching. These students' remarks included complaints referring 
to either no or late replies from teachers, insufficient lectures, and materials not matching the online setting.

Our teacher had so many technical issues that some students offered him help on how to open the different applications in online classes. I think he is not prepared for online teaching. All he does during classes is show PowerPoint slides.

\subsubsection{Activities and Homework}

The FGD members mentioned that their required activities and homework this semester proved overwhelming and stressful. One student from FGD1 expressed that she could not find time to complete all the required tasks because they were emailed and posted on Moodle in large quantities. She explained:

I was demotivated sometimes because I could not do some of the homework. I understand that these activities were designed to help students learn and make up for the usual classwork, but I think they were too many. I could not find time to do them all.

Others shared the same concern. However, they explained that these activities made them more autonomous in their studies. One student from FGD3 clarified that she is very motivated to do these activities because she has a goal in mind and knows that these activities will help her achieve that goal.

Yes, they are so many, but they help a lot. I used to do extra activities during in-person classes, and I will do the same now. I know that if I have to be better, then I have to do extra work.

\subsubsection{Lack of Group Work}

Most students spoke about the lack of group work as one factor that led to low motivation in remote online classes. They shared the same view about group works' importance and how it enhances learning and pushes students to do their best. A student from FGD4 expressed it this way:

I am used to studying in groups; it makes me a better student. If I do not understand some points during classes, I like to clarify them with my classmates first. I feel more comfortable asking them. Now, with remote online classes, it is not easy. Yes, we created a WhatsApp group, but it is not the same when you work face-to-face with a group of your peers. Group work is more fun, and it helps me and other students with doubts grasp the lesson.

Other students from other FGDs echoed this opinion. Their ideas included missing the physical closeness to their classmates and losing interest sometimes because of their peers' distance. One student from FGD2 complained that he could not feel the liveliness of online classes compared to in-person classes that he had in school because students hardly participated remotely:

You could hear the teacher call out students and encourage them to speak, but in vain. I think some students are having issues, and others join the class and get distracted by some other activities. This made me lose interest and caused me to be quiet myself.

\subsubsection{Assessments}

Online exams posed another concern for most students who participated in this study. They agreed that having online exams was one factor that demotivated them. Students raised several issues regarding online exams and how they affected their performance this semester. These issues included turning on the camera, the noise caused by the mics, and unclear instructions.

Some students expressed their frustration that new rules forced them to take makeup exams because of their areas' poor internet connection or because their teachers could not verify their identity during the exams. One student from FGD3 said:

I had to sit for a makeup exam because the invigilator had a blurry image of me during the first exam. This issue never happened to me in the last two semesters when all exams were on paper. I am sure that the invigilator could not identify all students, even those whose cameras were clear because they have never seen us before.

Another recurring issue arising when talking about assessments was malpractice. Some students confirmed that they knew cheating during online exams was easier than during in-person exams when asked about assessment. One student from FGD4 plainly stated that he had used Google Translate and had not been discovered. He explained that he knew it was illegal but mentioned that he could not attend online classes because of the poor internet connection.

I think everyone I know knows about it. I heard from my teachers that marks this semester are unprecedently very high and that they know some students are cheating. If some are cheating and getting away with it, do you think I will be motivated to study hard?

Other students talked about hearing stories about other students who get help during exams. One student said this:

I have a classmate who has been with me since joining the college. He hardly passed in the previous semesters. Now, he gets high marks and we all know he gets help because he brags about it. As a student, this demotivates me because I work hard and others getting good marks because they get help from others.

\subsection{Non-academic Factors Affecting Extrinsic Motivation}




\subsubsection{Internet Connection}

Based on the participants' answers in the FGDs, internet connection is the main factor that impacted their motivation during remote online studying. It was clear that almost all students had concerns about the internet signal in their areas. Poor internet connections represented the primary challenge that affected students' attendance and participation. One student described this as injustice:

Of course, I am demotivated by this. When we had face-to-face classes, we were all equal. We were exposed to the same quality of teaching because we were in the same classroom. Some of us are disadvantaged because we live in an area where the internet is awful. It makes it unfair for everyone.

One student from FGD3 explained that she had to be away from her family, and she rented a flat close to the university campus because of the poor internet connection in her hometown. It also caused other issues for her, as she had to undergo some of the authorities' restrictions during the pandemic. Students who lived in rural areas expressed the same concern.

A few students confirmed that they had stable internet connections at the beginning of their studies. However, the internet connection became unreliable after the reopening of schools last November, which caused heavy internet trafficking in their places.

\subsubsection{Family Responsibilities}

Several students conveyed that being at home while studying has not always helped motivate them to focus. Some students, particularly female students, mentioned they had to support their families by helping with housework. One female student said:

I am the eldest daughter, and I have six brothers and sisters. With all of us being at home because of the pandemic, you can imagine how much housework I had to do, from cleaning to cooking. It is expected from me as a girl to do so.

Another student explained that she was not aware of her parents' ongoing daily problems before the pandemic. After the lockdown, the quarrels intensified and being at home while studying was interrupted to a great extent. She felt she needed a significant distance from them to get enough time for focusing on her studies.

Some students had another experience with being at home. They explained that their families understood very well their need to focus on their studies, so they did not assign them any work during their online classes or when they were studying. Instead, they supported them during their studies by providing for their needs during this semester.

My family has been very supportive. They never interrupted me during my online live classes, and they always gave me enough space to study and do my homework.'

A fewer number of male students reported that they have family obligations centred around driving family members to different destinations. One male student from FGD4 described his family responsibilities this way

I got my driving licence last year, and since then, I became my family chauffeur. I take my mother to the hospital for her appointments and my little sisters to do shopping. After the suspension of in-person classes and the shift to online classes, this has increased a lot. I missed many lessons, and I got the third warning because of that. I appealed, and luckily, I was forgiven. This never happened when I had in-person classes because my family knew that I was at college.

\subsubsection{Distractions and the Lack of Quiet Setting}

At least one to three students in each FGD said their homes lacked the desired quietness to focus during their synchronous classes. They gave various reasons for this environment, including their families' size and the distractions that usually occur in their houses.

Our house is small. We have only two rooms, and my brothers and sisters were not engaged in school until recently. So, it was noisy all the time, and I refused to turn on the mic or the camera during the online classes because of the constant noise my younger siblings produce.

Other students talked about the many distractions they have when they are at home.

My family does a lot of things these days. Everyone is at home, and I get tempted to be part of the games my brothers play. If there is a movie or a match on TV, they would call me to join them.

Another student from FGD3 said that she lied several times to her parents about her classes so she could go out with them:

During this pandemic, we are all at home, and it causes stress. Knowing that someone from my family is going out even for a short time is a relief because it is an opportunity for me to accompany them and see the world outside.

\subsection{Attending Online Classes}

Most students agreed that they were intrinsically motivated to attend their synchronous classes at the beginning. However, this enthusiasm changed for some due to various reasons. One student elaborated on this issue:

At the beginning, I think everyone was enthusiastic about studying online. It is a new thing here. Later, we had daily issues with the internet during classes. I got frustrated, and I came to know that all lessons are recorded, so I can 
view them when I feel the need to.

Other students expressed different views on why they were disinterested in attending classes or were not attentive when attending online classes. These reasons included teachers' styles, the fact that classes are recorded and can be watched later, and the difficulty of interacting with teachers and other students due to large class sizes.

One male student from FGD2 explained that he has daily classes from 8 to $10 \mathrm{am}$, but he has to leave the lessons almost every day at 9 am because his younger brother uses the same laptop to attend his grade 10 classes.

I am new to the university and I need to attend all classes to improve my English and understand the difficult content of the math course, but my family can't afford buying another laptop. I think if we have im-person classes, I won't have to leave my classes like this.

More female students stated their commitment to attending online classes than male students. Additionally, more new intake students reported that they had regularly attended classes than students from the old intakes. One male student explained:

I am used to missing classes even before the pandemic. I only attend classes because I do not want to be dismissed from the university. I try to meet the minimum requirement.

\subsection{Face-to-face or Online?}

When asked whether they would prefer to study online or return to campus after the pandemic, most students preferred the in-person study. The sample students gave several reasons to support this preference. One student from FDG2 explained that his most important concern was assessments and that having exams on campus is a good reason for him to hope that classes will be conducted in-person again. Another new intake student from FGD1 explained that she expected to be a part of the college. Being new to college, she wanted to experience college life.

I want to meet my teachers and to have classes in-person. Online classes do not give me that experience. I have heard a lot from my friends about college and how different it is from school. I just want to feel that myself.

Other students provided different reasons for their preference for in-person education, including being more responsible about attendance and homework, interacting enthusiastically with teachers and classmates and avoiding the many distractions at home.

Yes, I liked the idea of being at home and not having to drive daily to the university. Now I know that I am a person who is motivated by his friends and teachers. I miss them, and I really want everything to go back to normal very soon.

\section{Conclusion and Discussion}

It is important to note that the participants were a mixture of new and old students in the GFP. New students were not acquainted with other students. However, the same applies to most students from previous intakes because they were placed randomly in different groups at each level without considering their previous groups. They had no experience with online learning and no knowledge of the applications used to deliver their classes.

One of the most critical findings in this study is that most participants agreed that internet connection was the number one non-academic obstacle during their first experience with remote online learning. Connectivity impacted their motivation heavily in their attendance and participation. This finding aligns with the results of a recent study conducted by Gares et al. (2020) at the University of Alberta. The researchers concluded that the poor internet connections represented a significant challenge to the students as they studied from their homes in rural areas. However, Aguilera-Hermida (2020) explored internet availability with 270 students who responded that they had fair access to the internet; notably, she cited that students with internet issues could not respond to the survey because it was posted online.

Family obligations were also a concern for the students in this study. During the pandemic's tumultuous time, families were forced to lock down, and many businesses were closed, making it necessary for all family members to share the various household responsibilities. In addition, the pandemic created financial difficulties for students' families. For example, some students were forced to share their laptops with their siblings. Similar findings were observed in recent studies that investigated the same issue in remote teaching during COVID-19 (Rahiem, 2021; Shin \& Hickey, 2020)

The sample students relied heavily on teachers. For example, teachers' style and swift email replies to students' concerns motivated learners to put more effort into their studies. This finding indicates that students are not yet autonomous in their learning; however, the students confirmed that many activities prepared them to handle the fewer number of contact hours. More studies are required to explore students' excessive dependence on their teachers during remote online learning.

The amount of homework and activities students must complete during remote online learning seemed overwhelming from some students' perspectives. Although most participants believed that teachers might have prepared these materials to compensate for the loss of face-to-face instruction, they felt burdened by them and discouraged about doing them. A similar finding can be found in Jeffery and Bauer's (2020) study of chemistry students, who stated that there were numerous online resources to read without teachers guiding them on which they should concentrate. 
Another critical finding in this study is that students are more likely to be demotivated in a setting where face-to-face classmate and teacher interaction is limited. Most participants in this study cited face-to-face interaction as a reason for their eagerness to return to campus. This finding matches a finding in LaBarbera's (2013) study that concluded a students' motivation to learn increases when students and instructors positively interact with each other.

It is clear from students' responses that most were motivated intrinsically at the beginning of their remote online learning experience. However, at least two-thirds of the participants' motivation decreased due to several extrinsic factors: e.g., family obligations, lack of a quiet space and poor or no internet access. This observation echoes the findings of Yates et al. (2020) who distributed a questionnaire to 1,975 students in six New Zealand high schools. The researchers associated the drop in students' motivation in online learning with contextual issues including family responsibilities: e.g., (a) obligations to care for siblings or help at home or on the farm, (b) distractions such as Netflix or online shopping, (c) unreachability of teachers or low peer support, (d) absence of extrinsic consequences, (e) and students' inability to differentiate the home from school. This result shows that extrinsic motivation factors might negatively impact high intrinsic motivation. This finding indicates that high intrinsic motivation is not always enough, and external factors can severely damage it.

Academic integrity in assessments is another essential factor that affects students' motivation to study and work hard. The participants' responses indicate that when the academic integrity of exams is at risk, their motivation to learn lowers. In other words, when students find it easier to commit malpractice during exams, they are more likely to lose interest in studying. Changing the types of exams and restricting the duration of assessments might help reduce this issue. For example, $\mathrm{Ng}$ (2020) reported no malpractice in a medical course after comparing the assessments' results between the standard invigilated exams before the pandemic and the take-home open book exam after the pandemic.

\subsection{Lessons for Teachers and Administrators}

As the first four questions were covered to a great extent in the finding and discussion sections, this section is dedicated to Question 5 of the current study in light of the participants' views and experiences. The changes in students' motivation during the remote instruction make it essential for teachers and administrators to consider the following lessons.

1. The lessons from this remote online learning experience should not be ignored once the pandemic is over. Teachers and administrators should be prepared for similar situations that necessitate the shift to remote online learning and teaching. Motivating students should be at the centre of these preparations because of the dilemmas and frustrations they will face in similar situations.

2. More alternatives should be available for students whose motivation is at risk because of slow internet connectivity in their areas or lack of quietness in their homes. Blended learning is one of the ideas that can be implemented in similar situations for students with difficulties accessing the internet. This practice will increase students' motivation and compensate for the loss in online-contact hours.

3. Assessments should be adapted to match situations. Online exams are different from invigilated, in-person exams. Teachers and administrators should think of novel ways to assess students objectively and efficiently without jeopardising the academic integrity of exams. Stifel et al. (2020) warns that these options should balance the health and safety needs of students and staff while respecting the legal and ethical standards required for assessment.

4. Amotivation among some students in emergency remote teaching should also be discussed and investigated. As this study found various factors that contributed to the change in students' motivation at this critical time, further studies are needed to investigate the results of students' amotivation in remote online learning that might be different from the consequences of students' amotivation in in-person education. Many researchers such as Vallerand et al. (1997), and Alivernini and Lucidi (2011) have studied the relationship between amotivation and students' dropout in face-to-face education. They concluded that the absence of motivation was high among students who left schools early or students who were not regular to their classes.

5. New policies related to remote learning and teaching have to be devised and implemented whenever required. These policies will avoid the uncertainty and unclarity that arise from changing the mode of teaching for all stakeholders. The absence of these has put students' motivation and academic integrity at risk and devising these policies will create a smoother and more efficient transition from face-to-face education to remote online learning and teaching.

\section{Limitations}

This study, examining motivation in an emergency remote teaching setting during the pandemic, has some limitations. Students and their families might experience other social and financial issues that could shape their attitudes towards learning. Some students were reluctant to share these issues in FGDs and were asked to share them in one-to-one interviews, but they refused.

Additionally, it is unclear whether online learning is a national motivated strategy that all HEIs will aim to foster and implement in the future. The adopted perspective might impact the colleges and universities and their 
commitment to online learning. It will also affect students' seriousness and their perceptions of online learning: making them believe that online learning is a temporary situation that will be over soon.

Furthermore, students' experiences in Semester 2 of the current academic year seem to differ from the experience of the students who participated in this study in Semester 1. Students are now more comfortable with remote online learning, and teachers are more prepared to avoid the many issues they faced in Semester 1. Therefore, another study might be crucial to assess the progress that all stakeholders have made and compare the findings of this study with the anticipated improvements in Semester 2.

The last limitation that can be observed is that the participants might not have been very open about some details, particularly about exams' academic integrity or criticising their teachers. Knowing that the researcher is an employee at the university, they might have been hesitant to share some further information thinking they will cause harm to them or other students. A researcher from outside the institutions might have different findings because the participants might be more comfortable sharing some ideas related to their motivation during remote online learning.

\section{Acknowledgment}

The author acknowledges the support of academic staff on the Doctoral Programme in Higher Education Research, Evaluation and Enhancement at Lancaster University from which this publication has arisen.

\section{References}

Ackerman, C. E. (2020). Self-determination theory of motivation: Why intrinsic motivation matters. Positive Psychology. Retrieved from https://positivepsychology.com/self-determination-theory/

Aguilera-Hermida, A. P. (2020). College students' use and acceptance of emergency online learning due to Covid-19. International Journal of Educational Research Open, 1, 100011. Retrieved from https://doi.org/10.1016/j.ijedro.2020.100011

Alivernini, F., \& Lucidi, F. (2011). Relationship between social context, self-efficacy, motivation, academic achievement, and intention to drop out of high school: A longitudinal study. The Journal of Educational Research, 104(4), 241-252. https://doi.org/10.1080/00220671003728062

Bell, J. (2014). Doing Your Research Project: A guide for first-time researchers. McGraw-Hill Education (UK).

Bowen, G. A. (2009). Document analysis as a qualitative research method. Qualitative research journal. https://doi.org/10.3316/QRJ0902027

Chen, K. C., \& Jang, S. J. (2010). Motivation in online learning: Testing a model of self-determination theory. Computers in Human Behavior, 26(4), 741-752. https://doi.org/10.1016/j.chb.2010.01.011

Cohen, L., Manion, L., \& Morrison, K. (2011). Research Methods in Education (7th ed). London: Routledge

Covid-19 Supreme Committee Holds First Meeting. (2020, March 12). Oman News Agency. Retrieved from https://omannews.gov.om/NewsDescription/ArtMID/392/ArticleID/10097/Covid-19-Supreme-Committee-Hol ds-First-Meeting

Crawford, J., Butler-Henderson, K., Rudolph, J., Malkawi, B., Glowatz, M., Burton, R., ... Lam, S. (2020). COVID-19: 20 countries' higher education intra-period digital pedagogy responses. Journal of Applied Learning \& Teaching, 3(1), 1-20. https://doi.org/10.37074/jalt.2020.3.1.7

Dhawan, S. (2020). Online learning: A panacea in the time of COVID-19 crisis. Journal of Educational Technology Systems, 49(1), 5-22. https://doi.org/10.1177/0047239520934018

Daniel, B. K., \& Harland, T. (2017). Higher education research methodology: A step-by-step guide to the research process. Routledge. https://doi.org/10.4324/9781315149783

Davies, L., \& Bentrovato, D. (2011). Understanding education's role in fragility: Synthesis of four situational analyses of education and fragility: Afghanistan, Bosnia and Herzegovina, Cambodia, Liberia. International Institute for Educational Planning. Retrieved from https://unesdoc.unesco.org/ark:/48223/pf0000191504

Deci, E. L., \& Ryan, R. M. (2012). Self-determination theory. In P. A. M. Van Lange, A. W. Kruglanski \& E. T. Higgins (Eds.), Handbook of theories of social psychology (pp. 416-436). Sage Publications Ltd. https://doi.org/10.4135/9781446249215.n21

Deci, E. L., \& Vansteenkiste, M. (2004). Self-determination theory and basic need satisfaction: Understanding human development in positive psychology. Ricerche di psicologia.

Dörnyei, Z. (1998). Motivation in second and foreign language learning. Language teaching, 31(3), 117-135. https://doi.org/10.1017/S026144480001315X

Dörnyei, Z. (2000). Motivation in action: Towards a process - oriented conceptualisation of student motivation. British journal of educational psychology, 70(4), 519-538. https://doi.org/10.1348/000709900158281

Gares, S. L., Kariuki, J. K., \& Rempel, B. P. (2020). Community matters: Student-instructor relationships foster student motivation and engagement in an emergency remote teaching environment. Journal of Chemical 
Education, 97(9), 3332-3335. https://doi.org/10.1021/acs.jchemed.0c00635

Hartnett, M., St George, A., \& Dron, J. (2011). Examining motivation in online distance learning environments: Complex, multifaceted, and situation-dependent. International Review of Research in Open and Distributed Learning, 12(6), 20-38. https://doi.org/10.19173/irrodl.v12i6.1030

Jeffery, K. A., \& Bauer, C. F. (2020). Students' responses to emergency remote online teaching reveal critical factors for all teaching. Journal of Chemical Education, 97(9), 2472-2485. https://doi.org/10.1021/acs.jchemed.0c00736

Keller, J. M. (2008). First principles of motivation to learn and e3-learning. Distance education, 29(2), 175-185. https://doi.org/10.1080/01587910802154970

Kim, K. J., \& Frick, T. W. (2011). Changes in student motivation during online learning. Journal of Educational Computing Research, 44(1), 1-23. https://doi.org/10.2190/EC.44.1.a

LaBarbera, R. (2013). The relationship between students' perceived sense of connectedness to the instructor and satisfaction in online courses. Quarterly Review of Distance Education, 14(4), 209.

Mohmmed, A. O., Khidhir, B. A., Nazeer, A., \& Vijayan, V. J. (2020). Emergency remote teaching during Coronavirus pandemic: the current trend and future directive at Middle East College Oman. Innovative Infrastructure Solutions, 5(3), 1-11. https://doi.org/10.1007/s41062-020-00326-7

Nowell, L. S., Norris, J. M., White, D. E., \& Moules, N. J. (2017). Thematic analysis: Striving to meet the trustworthiness criteria. International journal of qualitative methods, 16(1), 1609406917733847. https://doi.org/10.1177/1609406917733847

Rahiem, M. D. (2021). Remaining motivated despite the limitations: University students' learning propensity during the COVID-19 pandemic. Children and Youth Services Review, 120, 105802. https://doi.org/10.1016/j.childyouth.2020.105802

Rapanta, C., Botturi, L., Goodyear, P., Guàrdia, L., \& Koole, M. (2020). Online university teaching during and after the Covid-19 crisis: Refocusing teacher presence and learning activity. Postdigital Science and Education, 2(3), 923-945. https://doi.org/10.1007/s42438-020-00155-y

Shraim, K., \& Khlaif, Z. (2010). An e-learning approach to secondary education in Palestine: opportunities and challenges. Information Technology for Development, 16(3), 159-173. https://doi.org/10.1080/02681102.2010.501782

Schwan, A. (2020). Perceptions of Student Motivation and Amotivation. The Clearing House: A Journal of Educational Strategies, Issues and Ideas, 1-7. https://doi.org/10.1080/00098655.2020.1867490

Shin, M., \& Hickey, K. (2020). Needs a little TLC: examining college students' emergency remote teaching and learning experiences during COVID-19. Journal of Further and Higher Education, 1-14. https://doi.org/10.1080/0309877X.2020.1847261

Song, S. H. (2000). Research issues of motivation in web-based instruction. Quarterly Review of Distance Education, 1(3), 225-29.

Stifel, S. W., Feinberg, D. K., Zhang, Y., Chan, M. K., \& Wagle, R. (2020). Assessment During the COVID-19 Pandemic: Ethical, Legal, and Safety Considerations Moving Forward. School Psychology Review, 49(4), 438-452. https://doi.org/10.1080/2372966X.2020.1844549

Tamrat, W. (2021). Enduring the impacts of COVID-19: experiences of the private higher education sector in Ethiopia. Studies in Higher Education, 46(1), 59-74. https://doi.org/10.1080/03075079.2020.1859690

Vallerand, R. J., Fortier, M. S., \& Guay, F. (1997). Self-determination and persistence in a real-life setting: Toward a motivational model of high school dropout. Journal of Personality and Social Psychology, 72(5), 1161-1176. https://doi.org/10.1037/0022-3514.72.5.1161

Welch, C., \& Piekkari, R. (2006). Crossing language boundaries: Qualitative interviewing in international business. Management International Review, 46(4), 417-437. https://doi.org/10.1007/s11575-006-0099-1

Whalen, J. (2020). Should teachers be trained in emergency remote teaching? Lessons learned from the COVID-19 pandemic. Journal of Technology and Teacher Education, 28(2), 189-199.

Yates, A., Starkey, L., Egerton, B., \& Flueggen, F. (2020). High school students' experience of online learning during Covid-19: the influence of technology and pedagogy. Technology, Pedagogy and Education, 1-15. https://doi.org/10.1080/1475939X.2020.1854337

\section{Copyrights}

Copyright for this article is retained by the author(s), with first publication rights granted to the journal.

This is an open-access article distributed under the terms and conditions of the Creative Commons Attribution license (http://creativecommons.org/licenses/by/4.0/). 